\title{
Fracionamento de proteína e carboidratos em silagens de capim-elefante contendo subprodutos agrícolas ${ }^{1}$
}

\author{
Izabela Vieira Oliveira Andrade ${ }^{2}$, Aureliano José Vieira Pires ${ }^{3}$, Gleidson Giordano Pinto de \\ Carvalho ${ }^{4}$, Cristina Mattos Veloso ${ }^{3}$, Paulo Bonomo ${ }^{5}$
}

\author{
1 Projeto financiado pelo CNPq. \\ 2 UESB, Itapetinga, $B A$. \\ ${ }^{3}$ DTRA, UESB, Itapetinga, BA. \\ 4 UFBA, Salvador, BA. \\ ${ }^{5}$ DEBI, UESB, Itapetinga, $B A$.
}

RESUMO - Um experimento foi conduzido para determinar o fracionamento de carboidratos e proteína da silagem de capim-elefante contendo farelo de mandioca, casca de café farelo de cacau. Utilizou-se o delineamento experimental inteiramente casualizado, em esquema fatorial $3 \times 4$, composto de três subprodutos adicionados ao capim-elefante em quatro níveis (0, 10, 20 e 30\% da matéria natural), cada um com cinco repetições. O material foi ensilado em silos de PVC, que permaneceram fechados por 60 dias. O farelo de mandioca contribuiu para redução do teor de nitrogênio insolúvel em detergente ácido, apresentando os maiores valores para a fração A da proteína e para os teores das frações B1+B2. Em contrapartida, o farelo de cacau proporcionou acréscimo da fração C, aumentando significativamente o teor de proteína indisponível para os microrganismos ruminais. A adição do farelo de mandioca, seguido da casca de café, proporcionou os maiores teores de carboidratos totais em todos os níveis utilizados. As frações $\mathrm{A}+\mathrm{B} 1$ dos carboidratos aumentaram de acordo com os níveis de subprodutos adicionados, e a casca de café foi responsável pelo menor teor dessa fração nas silagens. O farelo de cacau favorece o aumento das frações nitrogenadas, porém a elevação do teor de nitrogênio insolúvel em detergente ácido, fração C, das silagens produzidas com este aditivo é um fator limitante. O farelo de mandioca aumenta o teor de carboidratos não-fibrosos da silagem, enquanto a casca de café e o farelo de cacau aumentam a fração não-digerível dos carboidratos.

Palavras-chave: CNCPS, ensilagem, frações, Pennisetum purpureum, valor nutritivo

\section{Protein and carbohydrate fractioning in elephantgrass silage with agricultural by-products}

\begin{abstract}
The experiment was conducted to determine fractioning of carbohydrate and protein of elephantgrass silage containing cassava meal, coffee hulls and cocoa meal. A completely randomized experimental design was used in a $3 \times 4$ factorial scheme, composed of three byproducts added to elephantgrass at four levels (0,10, 20 and 30\% of natural matter), each one with five repetitions. The material was ensiled in PVC silos, which remained closed for 60 days. Cassava meal contributed to reduce the content of acid detergent insoluble nitrogen, presenting the greatest values for protein A fraction and for the B1+B2 fraction contents. However, cocoa meal provided increment of $\mathrm{C}$ fraction, significantly increasing the content of unavailable protein for ruminal microorganisms. The addition of cassava meal, followed by coffee hulls provided the greatest total carbohydrate content in all the levels used. The A+B1 carbohydrate fractions increased according to the levels of added by-products, and coffee hulls was responsible for the lowest content of this fraction in the silages. Cocoa meal favors increase of nitrogenous fractions, but increase of acid detergent insoluble nitrogen, $\mathrm{C}$ fraction, of silages produced with this additive is a limiting factor. Cassava meal increase content of non-fibrous carbohydrates in the silage, while coffee hull and cocoa meal increase non-digestible fraction of carbohydrates.
\end{abstract}

Key Words: CNCPS, ensilage, fractions, nutritive value, Pennisetum purpureum

\section{Introdução}

A conservação da forragem do capim-elefante (Pennisetum purpureum Schum.) produzida na estação chuvosa é uma alternativa cada vez mais utilizada para suprir a escassez de volumoso na época seca, uma vez que esse capim apresenta alta produção de matéria seca (MS) e bom valor nutritivo. Entretanto, a presença de alto teor de umidade no momento ideal de corte e o baixo teor de carboidratos solúveis são fatores que inibem o adequado 
processo fermentativo, produzindo silagens de baixa qualidade, além de ocasionarem perdas de nutrientes pela elevada quantidade de efluente produzido (Andrade \& Lavezzo, 1998; McDonald, 1981).

No intuito de reduzir as perdas na ensilagem de capimelefante, uma das principais alternativas tem sido aumentar o teor de MS, por meio da adição de materiais absorventes, o que favorece a redução das perdas, além de contribuir para o incremento da composição química da silagem.

Os aditivos mais utilizados na ensilagem do capimelefante são os materiais secos que elevam o teor de MS da silagem e aumentam as chances de obter fermentação adequada. Entre esses materiais, citam-se as fontes de carboidratos, como fubá de milho, farelo de trigo, polpa cítrica e resíduos regionais da agroindústria (Silva et al., 2007).

De acordo com o Sistema de Cornell (CNCPS - Cornell Net Carbohydrate and Protein System), os alimentos são subdivididos em decorrência de suas características químicas e físicas, de degradação ruminal e digestibilidade pós-rúmen, visando minimizar as perdas de nutrientes, gerando informações que podem ser utilizadas para estimar o valor nutricional, o consumo e o desempenho animal (Fox et al., 1992; Sniffen et al., 1992).

Nos sistemas usuais de produção animal, os ruminantes obtêm a maioria dos nutrientes a partir de volumosos, salientando a necessidade de utilização de modelos mecanicistas para descrever a relação entre a composição bromatológica dos alimentos consumidos e a predição do desempenho animal (Fox et al., 1992) a partir da ação dos microrganismos ruminais e, portanto, para sua adequada caracterização, os nutrientes devem ser fracionados (Sniffen et al., 1992).

Este trabalho foi conduzido com o objetivo de avaliar a influência da adição de farelo de mandioca, casca de café e farelo de cacau na ensilagem do capim-elefante sobre a composição das frações que compõem as proteínas e os carboidratos.

\section{Material e Métodos}

O experimento foi conduzido no Laboratório de Forragicultura e Pastagem da Universidade Estadual do Sudoeste da Bahia, Campus de Itapetinga, Bahia, utilizando-se forragem de capim-elefante (Pennisetum purpureum Schum. cv. Napier) proveniente de uma capineira já estabelecida e localizada em solo classificado como chernossolo argilúvio, estruturado hipereutrófico, com textura argilosa e relevo ondulado (EMBRAPA, 1999), pertencente à Universidade Estadual do Sudoeste da Bahia, em Itapetinga, Bahia. Foram efetuados o corte de uniformização, a $10 \mathrm{~cm}$ do solo, e a adubação anual com 100 kg/ha de nitrogênio (N) (nitrocálcio), 100 kg/ha de $\mathrm{P}_{2} \mathrm{O}_{5}$ (superfosfato simples) e $60 \mathrm{~kg} / \mathrm{ha}$ de $\mathrm{K}_{2} \mathrm{O}$ (cloreto de potássio).

O delineamento foi inteiramente casualizado, em esquema fatorial $3 \times 4$, composto de três subprodutos adicionados ao capim-elefante (farelo de mandioca, casca de café e farelo de cacau), em quatro níveis (0, 10, 20 e 30\% da matéria natural, MN), cada um com cinco repetições.

O farelo de mandioca foi o resíduo sólido descartado na extração da goma, ou seja, foi proveniente da lavagem da mandioca triturada para produção de fécula, enquanto o farelo de cacau foi o subproduto resultante da industrialização da amêndoa do cacau para obtenção da manteiga do cacau e do chocolate. A casca de café é o resíduo proveniente do beneficiamento de grão de café por “via seca”, de modo que o fruto é seco em sua forma integral, resultando em resíduos de casca e pergaminho.

Após 40 dias de crescimento, período este que coincidiu com o adequado desenvolvimento (aproximadamente 1,2 - 1,5 m de altura) e bom valor nutritivo do capim, o que condiz com aos parâmetros recomendados para a produção de silagem de boa qualidade, o capim-elefante foi cortado manualmente a $10 \mathrm{~cm}$ do solo e desintegrado em partículas de aproximadamente $2 \mathrm{~cm}$ em ensiladeira estacionária. Após homogeneização com os respectivos aditivos, foi ensilado, em silos experimentais de PVC, com $50 \mathrm{~cm}$ de altura e $10 \mathrm{~cm}$ de diâmetro. As tampas dos silos eram providas de válvulas tipo "Bunsen” para permitir o escape dos gases oriundos da fermentação e possibilitar que as perdas de MS decorrentes do processo fermentativo fossem quantificadas. No fundo de cada silo foi colocado $1 \mathrm{~kg}$ de areia, separado da forragem por uma tela fina de plástico tipo sombrite, para captação do efluente proveniente da forragem ensilada. Em cada silo foram colocados $1.800 \mathrm{~g}$ da mistura capim-elefante e aditivo, compactada com auxílio de soquetes, obtendo-se massa específica de $600 \mathrm{~kg} / \mathrm{m}^{3}$ de matéria verde.

Antes do início do processo da ensilagem, amostras do capim-elefante, do farelo de mandioca, da casca de café e do farelo de cacau foram colhidas para análises. A composição bromatológica do capim-elefante e dos aditivos (Tabela 1) foram determinadas segundo metodologias descritas por Silva \& Queiroz (2002).

Após 60 dias, os silos foram abertos; amostras foram retiradas e submetidas à pré-secagem, por 72 horas, em estufa de ventilação forçada regulada a $55^{\circ} \mathrm{C}$ e, em seguida, processadas em moinho de facas tipo Willey, para posterior determinação do teor de matéria seca. 
Tabela 1 - Composição química dos alimentos antes da ensilagem, em porcentagem da matéria seca

\begin{tabular}{|c|c|c|c|c|}
\hline Item & Capim-elefante & Farelo de mandioca & Casca de café & Farelo de cacau \\
\hline Matéria seca & 15,9 & 84,5 & 87,9 & 86,9 \\
\hline Matéria orgânica & 90,3 & 98,7 & 94,4 & 90,2 \\
\hline Nitrogênio total & 1,1 & 0,3 & 1,5 & 3,0 \\
\hline Fibra em detergente neutro & 62,4 & 11,2 & 63,7 & 45,5 \\
\hline Fibra em detergente ácido & 40,9 & 6,9 & 42,9 & 32,6 \\
\hline Celulose & 34,3 & 5,5 & 29,5 & 16,9 \\
\hline NIDN/NT & 16,2 & 37,3 & 60,8 & 46,3 \\
\hline NIDA/NT & 13,5 & 17,2 & 38,3 & 35,8 \\
\hline
\end{tabular}

NIDN/NT: nitrogênio insolúvel em detergente neutro, em \% do nitrogênio total. NIDA/NT: nitrogênio insolúvel em detergente ácido, em \% do nitrogênio total.

Em seguida, as amostras foram submetidas às análises de nitrogênio total (NT), para a estimativa do teor de proteína bruta (PB), e de nitrogênio insolúvel em detergente neutro (NIDN) e nitrogênio insolúvel em detergente ácido (NIDA) segundo metodologias descritas por Silva \& Queiroz (2002).

A fração A das proteínas foi determinada após tratamento da amostra com ácido tricloroacético (TCA) a 10\%, conforme relatado por Licitra et al. (1996). A fração B3 foi obtida pela diferença entre os teores de NIDN e NIDA, enquanto a proteína verdadeira (frações B1 + B2) foi obtida pela diferença entre a fração A e o teor de NIDN. A fração C foi considerada nitrogênio insolúvel em detergente ácido (NIDA).

A porcentagem de carboidratos totais (CT) foi obtida pela equação proposta por Sniffen et al. (1992): CT = $100-(\%$ PB + \% EE + \% cinzas). Os carboidratos fibrosos foram obtidos a partir da FDN corrigida para cinzas e proteína (FDNcp); os carboidratos não-fibrosos (CNF), ou seja, as frações $A+B 1$, pela diferença entre os carboidratos totais e a FDNcp (Hall, 2003) e a fração C, pela FDN indigestível após 240 horas de incubação in situ, descrita por Casali et al. (2008). A fração B2, correspondente à fração disponível da fibra, foi obtida pela diferença entre a FDNcp e a fração C.

Os resultados foram submetidos à análise de variância, considerando como fontes de variação os aditivos, seus níveis de inclusão e a interação entre esses fatores, sendo a interação desdobrada, ou não, de acordo com a sua significância. A influência dos níveis de inclusão dos aditivos foi avaliada por análise de regressão, tomando como base o valor do coeficiente de determinação. Para testar a influência dos aditivos foi aplicado o teste de Tukey, adotando-se o nível de 5\% de probabilidade.

\section{Resultados e Discussão}

O teor de nitrogênio não-proteico das silagens, representado pela fração $\mathrm{A}$, como porcentagem do nitrogênio total, não foi influenciado $(\mathrm{P}>0,05)$ pela interação entre os aditivos e os níveis de inclusão dos subprodutos (Tabela 2).

A fração A das silagens de capim-elefante sofreu efeito linear decrescente $(\mathrm{P}<0,05)$ dos níveis de aditivos, com redução de 0,31 unidade percentual a cada $1 \%$ de aumento no nível do subproduto.

Cabral et al. (2004) obtiveram valor de 56,9\% da fração A da silagem de capim-elefante. Esses autores atribuíram o elevado teor desta fração ao baixo teor de MS da silagem de capim-elefante (18,3\%), um indicativo da ocorrência de maior proteólise durante a fermentação. O comportamento dos resultados obtidos no presente estudo se assemelha ao observado por Cabral et al. (2004), pois a silagem de capimelefante sem adição de co-produtos apresentou 31,9\% de fração A (\% do NT). Embora esse valor tenha sido inferior aos valores de fração B1 + B2 (\% do NT), é considerado alto. Vale ressaltar, entretanto, que o valor de MS foi baixo, apenas de $18,7 \%$. Silagens com teores de MS semelhantes podem apresentar fração A diferentes em decorrência de vários fatores, dentre eles o teor de PB da forrageira antes da ensilagem e também do processo fermentativo.

Os teores de proteína verdadeira, representada pelas frações B1 + B2, em porcentagem do nitrogênio total, não foram alterados $(\mathrm{P}>0,05)$ pela interação entre os aditivos $\mathrm{e}$ os níveis utilizados (Tabela 2). As silagens contendo farelo de mandioca apresentaram maiores teores dessa fração (45,6\%), enquanto aquelas contendo casca de café apresentaram valores intermediários $(33,3 \%)$, indicando que a adição de farelo de cacau proporcionou os menores teores dessa fração.

As silagens de capim-elefante sem a inclusão dos subprodutos apresentaram valor das frações B1 + B2 de $49,5 \%$ do NT, bem acima dos encontrados por Cabral et al. (2004) para as silagens de milho (34,6\% da PB) e de capimelefante (22,4\% da PB). As frações B1 + B2, por sua maior taxa de degradação ruminal em comparação à fração B3, 
Tabela 2 - Frações proteicas de silagens de capim-elefante contendo farelo de mandioca, casca de café ou farelo de cacau

\begin{tabular}{|c|c|c|c|c|c|c|c|}
\hline \multirow[t]{2}{*}{ Aditivo } & \multicolumn{4}{|c|}{ Nível do aditivo (\% matéria natural) } & \multirow[t]{2}{*}{ Média } & \multirow[t]{2}{*}{ Equação de regressão } & \multirow[t]{2}{*}{$\mathrm{R}^{2}$} \\
\hline & 0 & 10 & 20 & 30 & & & \\
\hline \multicolumn{8}{|c|}{ Matéria seca (\%) } \\
\hline Casca de café (CC) & 18,7 & $25,0 \mathrm{a}$ & $32,2 \mathrm{a}$ & $34,7 b$ & 30,6 & $\hat{Y}=19,38+0,5512 * C C$ & 0,97 \\
\hline Farelo de cacau (FC) & 18,7 & $22,9 a$ & $29,7 b$ & $37,6 a$ & 30,1 & $\hat{Y}=17,74+0,6325 * F C$ & 0,98 \\
\hline Média & 18,7 & 23,7 & 29,8 & 35,7 & 27,0 & & \\
\hline Farelo de mandioca (FM) & 31,9 & 36,7 & 30,9 & 31,6 & $33,1 \mathrm{a}$ & & \\
\hline Casca de café (CC) & 31,9 & 25,2 & 21,2 & 21,9 & $22,8 b$ & & \\
\hline Farelo de cacau (FC) & 31,9 & 20,4 & 17,9 & 14,9 & $17,7 \mathrm{c}$ & & \\
\hline Média & 31,9 & 27,4 & 23,3 & 22,8 & 26,4 & $\hat{Y}=31,105-0,3151 * X$ & 0,92 \\
\hline CV (\%) & 12,2 & & & & & & \\
\hline Média & 49,5 & 36,8 & 37,4 & 34,8 & 39,7 & $\hat{Y}=48,682-1,189 * X+0,0252 * X^{2}$ & 0,89 \\
\hline CV (\%) & 8,8 & & & & & & \\
\hline \multicolumn{8}{|c|}{ Fração B3 (\%NT) } \\
\hline Farelo de mandioca (FM) & 7,3 & $8,9 b$ & $13,8 \mathrm{a}$ & $17,0 \mathrm{a}$ & 13,2 & $\hat{Y}=6,6422+0,3402 * F M$ & 0,96 \\
\hline Casca de café (CC) & 7,3 & $19,3 a$ & $16,5 \mathrm{a}$ & $17,7 \mathrm{a}$ & 17,9 & $\hat{Y}=8,2285+1,0959 * \mathrm{CC}-0,027 * \mathrm{CC}^{2}$ & 0,79 \\
\hline Farelo de cacau (FC) & 7,3 & $23,9 a$ & $16,2 \mathrm{a}$ & $15,0 \mathrm{a}$ & 18,4 & $\hat{\mathrm{Y}}=8,8355+1,4894 * \mathrm{FC}-0,0445 * \mathrm{FC}^{2}$ & 0,66 \\
\hline Média & 7,3 & 17,4 & 15,5 & 16,6 & 14,2 & & \\
\hline CV (\%) & 22,6 & & & & & & \\
\hline \multicolumn{8}{|c|}{ Fração C (\%NT) } \\
\hline Farelo de mandioca (FM) & 11,2 & $8,3 b$ & $8,9 \mathrm{c}$ & $6,7 c$ & 8,0 & $\hat{Y}=10,735-0,1295 * F M$ & 0,79 \\
\hline Casca de café (CC) & 11,2 & $21,4 \mathrm{a}$ & $27,8 b$ & $28,9 b$ & 26,0 & $\hat{Y}=11,163+1,2696 * C C-0,0225 * C^{2}$ & 0,99 \\
\hline Farelo de cacau (FC) & 11,2 & $25,5 a$ & $34,4 \mathrm{a}$ & $41,6 a$ & 33,8 & $\hat{Y}=11,436+1,5264 * \mathrm{FC}-0,0175 * \mathrm{FC}^{2}$ & 0,99 \\
\hline
\end{tabular}

Médias seguidas de letras diferentes, na coluna, diferem $(\mathrm{P}<0,05)$ pelo teste Tukey. $*(\mathrm{P}<0,05)$; CV - coeficiente de variação.

tende a ser extensivamente degradada no rúmen (Sniffen et al., 1992), contribuindo para o atendimento aos requisitos de nitrogênio dos microrganismos.

Para os teores de proteína associada à parede celular e de lenta degradação, representada pela fração B3, como porcentagem do nitrogênio total, foi verificado efeito $(\mathrm{P}<0,05)$ da interação dos aditivos e dos níveis de inclusão utilizados (Tabela 2). O aumento dos níveis de farelo de mandioca teve efeito linear $(\mathrm{P}<0,05)$ nos teores dessa fração, promovendo acréscimo de 0,34 unidade percentual a cada $1 \%$ de farelo de mandica adicionado ao capim-elefante no momento da ensilagem. Para as adições de casca de café e farelo de cacau foram detectados efeitos quadráticos $(\mathrm{P}<0,05)$, estimando-se valores máximos de 19,3 e 21,3\% para fração B3 nos níveis de 20,3 e 16,7\% de café e farelo de cacau, respectivamente.

Pires et al. (2009) adicionaram 15\% de farelo de cacau ao capim-elefante no momento da ensilagem e observaram aumento da fração B3, com valor bem próximo ao encontrado neste estudo para a inclusão do mesmo tipo de aditivo.
Como esta fração é caracterizada pelos teores de proteínas ligadas à parede celular, esse efeito pode ser atribuído às adições dos subprodutos na ensilagem do capim-elefante. Esses aditivos apresentaram elevados teores de NIDN e NIDA (Tabela 1), o que ocasionou elevação dos teores de proteína não-degradada no rúmen, com maiores valores de B3.

Para os teores de proteína insolúvel em detergente ácido, representada pela fração $\mathrm{C}$, como porcentagem do nitrogênio, foi verificado efeito $(\mathrm{P}<0,05)$ da interação entre os aditivos e seus níveis de inclusão na ensilagem (Tabela 2). Conforme a análise de regressão, houve efeito linear decrescente $(\mathrm{P}<0,05)$ da inclusão de farelo de mandioca à silagem de capim-elefante, que apresentou redução estimada de 0,13 unidade percentual para cada $1 \%$ de farelo de mandioca adicionado.

Foi observado comportamento quadrático $(\mathrm{P}<0,05)$ da fração C em resposta aos níveis de casca de café e farelo de cacau na ensilagem. Os valores máximos estimados dessa fração foram de $46,9 \%$ para a casca de café e $44,7 \%$ para o 
farelo de cacau nos níveis de 28,2 e $43,6 \%$ desses subprodutos.

De acordo com Sniffen et al. (1992), o acréscimo nos teores da fração C (NIDA) tem como agravante a formação de produtos de Maillard causada pelo aquecimento dentro do silo, provocado por fermentações indesejáveis decorrentes do elevado teor de umidade da forragem. Neste caso, o aumento do teor desta fração pode ser atribuído aos níveis de casca de café e farelo de cacau, que apresentaram em sua composição (Tabela 1) teores elevados de NIDA em relação ao capim-elefante.

A determinação das características das frações proteicas dos alimentos permite estimar seus respectivos teores, bem como o maior ou menor escape de nitrogênio ruminal. Com essas informações, torna-se possível desenvolver estratégias nutricionais para melhorar a utilização do nitrogênio, tanto pelos microrganismos ruminais quanto pelo animal hospedeiro (Cabral et al., 2000).

Foi verificado efeito da interação entre os aditivos e os níveis de inclusão dos subprodutos $(\mathrm{P}<0,05)$ sobre as concentrações de carboidratos totais das silagens (Tabela 3).
Conforme a análise de regressão, os níveis de farelo de cacau provocaram aumento linear do teor de carboidratos totais, estimando-se aumento de 0,28 unidade percentual para cada $1 \%$ desse aditivo. A adição da casca de café teve efeito quadrático $(\mathrm{P}<0,05)$, com teor mínimo estimado de 78,9\% para o nível de 18,4\% desse aditivo. A adição do farelo de cacau ao capim-elefante também apresentou comportamento quadrático $(\mathrm{P}<0,05)$, com ponto de mínima estimado de 73,6\% para o nível de $24,2 \%$ desse aditivo.

A redução dos teores de carboidratos totais pode estar relacionada aos maiores teores de proteína bruta e extrato etéreo do farelo de cacau, que foram 11,6 e 0,4 pontos percentuais superiores aos do capim-elefante (Tabela 1). O elevado teor dessas frações pode interferir na estimativa do teor dos carboidratos totais, causando sua redução (Sniffen et al., 1992).

A análise estatística dos teores de carboidratos nãofibrosos (CNF), representados pelas frações $\mathrm{A}+\mathrm{B} 1$ das silagens, confirmou efeito $(\mathrm{P}<0,05)$ da interação entre os aditivos e seus níveis de adição na silagem (Tabela 3). A adição de farelo de mandioca e de farelo de cacau provocou efeito linear crescente $(\mathrm{P}<0,05)$ nas frações $\mathrm{A}+\mathrm{B} 1$ dos carboidratos, promovendo aumentos de 1,5 e 0,8 unidade

Tabela 3 - Composição em carboidratos totais da parede celular de silagens de capim-elefante contendo farelo de mandioca, casca de café ou farelo de cacau

\begin{tabular}{|c|c|c|c|c|c|c|c|}
\hline \multirow[t]{2}{*}{ Aditivo } & \multicolumn{4}{|c|}{ Nível de inclusão (\%MN) } & \multirow[t]{2}{*}{ Média } & \multirow[t]{2}{*}{ Equação de regressão } & \multirow[t]{2}{*}{$\mathrm{R}^{2}$} \\
\hline & 0 & 10 & 20 & 30 & & & \\
\hline \multicolumn{8}{|c|}{ Carboidratos totais (\%MS) } \\
\hline Farelo de mandioca (FM) & 80,6 & $83,0 \mathrm{a}$ & $85,9 a$ & $89,1 \mathrm{a}$ & 86,0 & $\hat{Y}=80,363+0,2847 * \mathrm{FM}$ & 0,99 \\
\hline Casca de café (CC) & 80,6 & $78,7 \mathrm{~b}$ & $79,4 b$ & $79,3 b$ & 79,1 & $\hat{Y}=80,392-0,1618 * C C+0,0044 * C^{2}$ & 0,70 \\
\hline Farelo de cacau (FC) & 80,6 & $75,4 c$ & $74,4 \mathrm{c}$ & $73,8 \mathrm{c}$ & 74,5 & $\hat{Y}=80,361-0,5579 * F C+0,0115 * \mathrm{FC}^{2}$ & 0,97 \\
\hline Média & 80,6 & 79,0 & 79,9 & 80,7 & 80,0 & & \\
\hline CV (\%) & 2,0 & & & & & & \\
\hline \multicolumn{8}{|c|}{ Fração A + B1 (\% carboidratos totais) } \\
\hline Farelo de mandioca (FM) & 25,9 & $49,6 \mathrm{a}$ & $65,0 \mathrm{a}$ & $70,5 a$ & 61,7 & $\hat{Y}=30,348+1,4939 * F M$ & 0,93 \\
\hline Casca de café (CC) & 25,9 & $25,9 c$ & $25,9 c$ & $25,8 \mathrm{c}$ & 25,9 & $\hat{Y}=\bar{Y}=25,9$ & - \\
\hline Farelo de cacau (FC) & 25,9 & $35,4 b$ & $45,1 b$ & $49,0 \mathrm{~b}$ & 43,2 & $\hat{Y}=27,009+0,7909 * \mathrm{FC}$ & 0,96 \\
\hline Média & 25,9 & 37,0 & 45,4 & 48,5 & 39,3 & & \\
\hline CV (\%) & 9,6 & & & & & & \\
\hline \multicolumn{8}{|c|}{ Fração B2 (\% carboidratos totais) } \\
\hline Farelo de mandioca (FM) & 38,5 & 26,9 & 19,1 & 16,2 & $20,7 \mathrm{a}$ & & \\
\hline Casca de café (CC) & 38,5 & 27,1 & 18,0 & 12,1 & $19,1 \mathrm{a}$ & & \\
\hline Farelo de cacau (FC) & 38,5 & 27,6 & 12,8 & 7,6 & $16,0 \mathrm{~b}$ & & \\
\hline Média & 38,5 & 27,2 & 16,6 & 12,0 & 23,6 & $\hat{Y}=37,092-0,9015^{*} X$ & 0,97 \\
\hline CV (\%) & 19,5 & & & & & & \\
\hline \multicolumn{8}{|c|}{ Fração C (\% carboidratos totais) } \\
\hline Farelo de mandioca (FM) & 25,9 & $23,5 c$ & $15,9 \mathrm{c}$ & $13,3 c$ & 17,6 & $\hat{Y}=26,475-0,4546 * F M$ & 0,95 \\
\hline Casca de café (CC) & 25,9 & $49,4 \mathrm{a}$ & $56,1 \mathrm{a}$ & $25,8 a$ & 43,8 & $\hat{Y}=24,889+4,1014 * C C-0,1346 * C^{*} C^{2}$ & 0,97 \\
\hline Farelo de cacau (FC) & 25,9 & $37,0 \mathrm{~b}$ & $42,1 b$ & $43,4 b$ & 40,8 & $\hat{Y}=26,004+1,308 * \mathrm{FC}-0,0244 * \mathrm{FC}^{2}$ & 0,99 \\
\hline Média & 25,9 & 36,6 & 38,0 & 27,5 & 37,3 & & \\
\hline CV (\%) & 9,1 & & & & & & \\
\hline
\end{tabular}

Médias seguidas de letras diferentes na coluna diferem $(\mathrm{P}<0,05)$ pelo teste Tukey.

$*(\mathrm{P}<0,05) ; \mathrm{CV}$ - coeficiente de variação. 
percentual a cada $1 \%$ desses aditivos. Para a casca de café, não foi verificado efeito $(\mathrm{P}>0,05)$, estimando-se teor médio de $25,9 \%$ desta fração. A adição de farelo de mandioca demonstrou superioridade quanto aos teores desta fração, em todos os níveis de inclusão utilizados (10, 20 e 30\% da MN).

Os teores mais elevados das frações A + B1 das silagens contendo farelo de mandioca e farelo de cacau, em comparação à silagem sem aditivos, podem estar associados aos menores teores de FDNcp, que reduziram com a adição dos subprodutos (10, 20 e $30 \%$ da MN).

Pereira et al. (2000) relataram que os alimentos que contêm elevados teores das frações A + B1 são excelentes fontes de energia para o desenvolvimento de microrganismos que utilizam carboidratos não-fibrosos, portanto, é necessária a inclusão de fontes proteicas de rápida e média degradação no rúmen, tendo como finalidade a sincronização entre a liberação de energia e nitrogênio.

Para os teores dos componentes da parede celular que correspondem à fração potencialmente degradável (B2) das silagens de capim-elefante, não foi verificado efeito $(P>0,05)$ da interação entre os aditivos e os níveis de inclusão (Tabela 3).

A adição de farelo de mandioca e da casca de café ao capim-elefante resultou em silagens com teores semelhantes da fração B2 (20,7 e 19,1\%, respectivamente), enquanto a adição do farelo de cacau proporcionou o menor teor (16\%). O teor da fração B2 diminuiu com a adição de farelo de mandioca, casca de café e farelo de cacau ao capim-elefante, confirmando efeito linear decrescente $(\mathrm{P}<0,05)$, com redução de 0,9 unidade percentual a cada $1 \%$ de inclusão de farelo de mandioca, casca de café e farelo de cacau. Essa redução pode ser explicada pelos menores teores de FDN (Carvalho et al., 2007) nos aditivos em relação ao capim-elefante (Tabela 1).

A diminuição da fração B2 coincidiu com o aumento das frações A + B1, o que reforça a hipótese de decomposição natural da parede celular provocada pela fermentação dentro do silo, o que contribui para o aumento das frações de alta disponibilidade (Barcelos et al., 2001).

Mello \& Nörnberg (2004) relataram que a diferença nas frações de carboidratos entre culturas está relacionada às diferenças nas características estruturais das plantas e verificaram em estudo sobre fracionamento de carboidratos das silagens de milho, sorgo e girassol diferenças significativas nos teores da fração B2 entre as culturas ensiladas. A silagem de sorgo apresentou valor mais elevado dessa fração (488,1 g/kg de MS) em comparação às silagens de milho e girassol (379,4 e 220,2 g/kg de MS, respectivamente).

A análise estatística da fração $C$ de carboidratos das silagens comprovou efeito $(P<0,05)$ da interação entre os aditivos e os níveis utilizados (Tabela 3). A adição de farelo de mandioca causou efeito linear decrescente $(\mathrm{P}<0,05)$ na fração $\mathrm{C}$ das silagens, cujo decréscimo foi estimado em 0,45 unidade percentual a cada $1 \%$ de farelo de mandioca adicionado ao capim-elefante. Para as adições de casca de café e farelo de cacau, foi observado efeito quadrático $(\mathrm{P}<0,05)$, com teores máximos estimados em 56,1 e 43,5\% desta fração para os níveis de 15 e 26,8\% de inclusão desses aditivos, respectivamente.

É possível que a redução da fração $C$ com a adição de farelo de mandioca ao capim-elefante seja decorrente do baixo teor de lignina neste aditivo (1,6\% da MS), enquanto para a casca de café e o farelo de cacau houve aumento de fração $C$, em decorrência dos altos teores de lignina nesses aditivos, 13,0 e 14,8\%, respectivamente. A redução da fração C com a inclusão de farelo de mandioca pode favorecer o consumo, fator determinante da produção animal intensiva. Além disso, a redução dessa fração causaria aumento da disponibilidade de energia, como relatado por Cabral et al. (2002), que, estudando as proporções de grãos na ensilagem de milho, verificaram redução de 26,6 para $9,3 \%$ dos carboidratos totais na fração C na proporção de 0 e $60 \%$ de grãos nas silagens. Contudo, os resultados encontrados neste estudo somente foram decrescentes para as silagens com farelo de mandioca, que apresentaram, dessa forma, boa disponibilidade nutricional.

Assim, a caracterização das frações que constituem os carboidratos dos alimentos representa importante instrumento para adequação de dietas formuladas visando à maximização do desenvolvimento microbiano ruminal e, por consequência, a melhor predição do desempenho animal, e racionaliza a utilização dos recursos nos sistemas de produção.

\section{Conclusões}

O farelo de cacau favorece o aumento das frações nitrogenadas, porém a elevação do teor de nitrogênio insolúvel em detergente ácido, fração C, das silagens produzidas com esse aditivo constitui-se em fator limitante. O farelo de mandioca aumenta o teor de carboidratos nãofibrosos da silagem, enquanto a casca de café e o farelo de cacau aumentam a fração não digerível dos carboidratos. 


\section{Referências}

ANDRADE, J.B.; LAVEZZO, W. Aditivos na ensilagem do capimelefante. I. Composição bromatológica das forragens e das respectivas silagens. Revista Pesquisa Agropecuária Brasileira, v.33, n.11, p.1859-1872, 1998.

BARCELOS, A.F.; PAIVA, P.C.A.; PÉREZ, J.R.O. et al. Estimativa das frações dos carboidratos, da casca de café e polpa desidratada de café (Coffea arabica L.) armazenadas em diferentes períodos. Revista Brasileira de Zootecnia, v.30, n.5, p.1566-1571, 2001.

CABRAL, L.S.; VALADARES FILHO, S.C.; MALAFAIA, P.A.M. et al. Frações protéicas de alimentos tropicais e sua taxas de digestão estimadas pela incubação com proteases ruminais. Revista Brasileira de Zootecnia, v.29, n.6, p.2316-2324, 2000 (supl.2).

CABRAL, L.S.; VALADARES FILHO, S.C.; DETMANN, E. et al. Cinética ruminal das frações de carboidratos, produção de gás, digestibilidade in vitro da matéria seca e NDT estimado da silagem de milho com diferentes proporções de grãos. Revista Brasileira de Zootecnia, v.31, n.6, p.2332-2339, 2002.

CABRAL, L.S.; VALADARES FILHO, S.C.; DETMANN, E. et al. Taxas de digestão das frações protéicas e de carboidratos para as silagens de milho e de capim-elefante, o feno de capim-tifton-85 e o farelo de soja. Revista Brasileira de Zootecnia, v.33, n.6, p.1573-1580, 2004.

CARVALHO, G.G.P.; GARCIA, R.; PIRES, A.J.V. et al. Fracionamento de carboidratos de silagem de capim-elefante emurchecido ou com farelo de cacau. Revista Brasileira de Zootecnia, v.36, n.4, p.1000-1005, 2007 (supl.).

CASALI, A.O.; DETMANN, E.; VALADARES FILHO, S.C. et al. Influência do tempo de incubação e do tamanho de partículas sobre os teores de compostos indigestíveis em alimentos e fezes bovinas obtidos por procedimentos in situ. Revista Brasileira de Zootecnia, v.37, n.2, p.335-342, 2008.
EMPRESA BRASILEIRA DE PESQUISA AGROPECUÁRIA EMBRAPA. Sistema brasileiro de classificação de solos. Brasília, 1999. 412p.

FOX, D.G.; SNIFFEN, C.J.; O'CONNOR, J.D. A net carbohydrate and protein system for evaluating cattle diets: III. Cattle requirements and diet adequacy. Journal of Animal Science, v.70, n.12, p.3578-3596, 1992.

HALL, M.B. Challenges with nonfiber carbohydrate methods. Journal of Animal Science, v.81, p.3226-3232, 2003.

LICITRA, G.; HERNANDES, T.M.; VAN SOEST, P.J. Standardization of procedures for nitrogen fractionational of ruminant feeds. Animal Feed Science and Technology, v.57, n.4, p.347-358, 1996.

McDONALD, P. The biochemistry of silage. Nova York: Jonh Wiley \& Sons, 1981. 226p.

MELLO, R.; NÖRNBERG, J.L. Fracionamento dos carboidratos e proteínas de silagens de milho, sorgo e girassol. Revista Ciência Rural, v.34, n.5, p.1537-1542, 2004.

PEREIRA, E.S.; QUEIROZ, C.A.; PAULINO, M.F. et al. Determinação das frações protéicas e de carboidratos e taxas de degradação in vitro da cana-de-açúcar, da cama de frango e do farelo de algodão. Revista Brasileira de Zootecnia, v.29, n.6, p.1887-1893, 2000.

PIRES, A.J.V.; CARVALHO, G.G.P.; GARCIA, R. Fracionamento de carboidratos e proteínas de silagens de capim-elefante com casca de café, farelo de cacau ou farelo de mandioca. Revista Brasileira de Zootecnia, v.38, n.3, p.422-427, 2009.

SILVA, D.J.; QUEIROZ, A.C. Análise de alimentos: métodos químicos e biológicos. Viçosa, MG: UFV, 2002. 235p.

SILVA, F.F.; AGUIAR, M.S.M.A.; VELOSO, C.M. et al. Bagaço de mandioca na ensilagem do capim-elefante: qualidade das silagens e digestibilidade dos nutrientes. Arquivo Brasileiro de Medicina Veterinária e Zootecnia, v.59, n.3, p.719-729, 2007.

SNIFFEN, C.J., O'CORNOR, J.D., VAN SOEST, P.J. et al. A net carbohydrate and protein system for evaluating cattle diets: II. Carbohydrate and protein availability. Journal of Animal Science, v.70, n.12, p.3562-3577, 1992. 